\title{
2 The utility of the modified frailty index for risk stratification in patients undergoing spine surgery
}

\author{
Charles Fisher, MD, MHSc, FRCSC, and Jin Tee, MD, FRACS, MBBS, BMedSci
}

Department of Orthopedics, University of British Columbia, Vancouver, British Columbia, Canada

\section{$\mathrm{T}$} HE ability to accurately and consistently predict how well a patient will tolerate elective spine surgery is one of the most challenging issues spine surgeons face. Risk stratification is not only essential in preoperative patient counseling, but is also a critical component of resource utilization and planning. Although we must rely on our clinical judgment, evidence-based assessment tools can be valuable, if they are simple and time-efficient. Previously, the American Society of Anesthesiologists (ASA) physical status classification grade was investigated for this purpose, using data from the Scoliosis Research Society Morbidity and Mortality database; it showed a significant correlation of higher preoperative ASA grades and increased morbidity in patients undergoing complex spine surgery. ${ }^{3}$ With the burgeoning geriatric patient population, another potentially important concept mitigating perioperative and postoperative complication risk stratification is frailty, especially in less complex spine procedures. As an adjunct to the ASA, the authors investigated whether the modified frailty index $(\mathrm{mFI})$ correlates with higher risks of postoperative complications.

This study has a strong rationale and a clear purpose; to investigate whether the $\mathrm{mFI}$ is predictive of systemic and wound-related complications in patients undergoing mainly secondary-level spine surgeries. ${ }^{1}$ The study design is a retrospective case series using a large patient cohort that was prospectively collected by the American College of Surgeons National Surgical Quality Improvement Program (ACS NSQIP) during a 4-year period (2006-2010). The study design is appropriate for the research question asked, given the mFI's phase of development related to spine surgery. The study is well powered and the results generalizable, given the large multicenter national database and that the majority of the cases were "routine" spine surgeries. The ACS NSQIP has audit procedures in place to optimize data validity. The mFI has not un- dergone formal intra- and interrater reliability testing, although the binary variables used to construct the $\mathrm{mFI}$ make it relatively simple to use.

The $\mathrm{mFI}$ was assessed using 30-day risk-adjusted surgical outcomes ${ }^{7}$ and variables making up the prevalidated Canadian Study of Health and Aging Frailty Index (CSHA-FI). ${ }^{8}$ This enabled the satisfactory assessment of 16 NSQIP and 11 CSHA-FI variables. The calculation and cutoff for significant frailty of the mFI had previously been published by other surgical specialties. ${ }^{2,6,8}$ The authors stated that this cutoff was chosen because spine procedures are generally not offered to moderately or severely frail patients. This rationale, however, may not be entirely accurate. With minimally invasive techniques and navigation rapidly evolving, patients with significant spinal pathology and poor health-related quality of life scores are likely to be offered surgery, despite a higher risk profile. Further studies will be required, including a subgroup analysis of this study's population to provide greater insight into these patient populations.

With regard to statistical analysis, the authors used standard and appropriate univariate and multivariate analyses to assess the association of the $\mathrm{mFI}$ to postoperative outcomes and 30-day mortality. The assessment and prediction of perioperative and postoperative complications in patients undergoing elective primary and secondary spine surgery is essential and often undervalued. This is particularly important in older and frail patients whose health-related quality of life and resource utilization seem more closely tied to surgical adverse events, whether early or late. Furthermore, patient symptoms, surgical indication, and surgical technique also vary. 4,5

The authors should be congratulated for introducing a risk index that objectively quantifies both surgical site and systemic related surgical risk. The study is statistically sound and provides valid results within the restraints of a 
retrospective design. However, for the mFI to be considered for widespread adoption it must undergo prospective evaluation is this distinct patient population.

http://thejns.org/doi/abs/10.3171/2016.1.SPINE151261

\section{References}

1. Ali R, Schwalb JM, Nerenz DR, Antoine HJ, Rubinfeld I: Modified Frailty Index predicts 30-day morbidity and mortality from spine surgery, J Neurosurg Spine [epub ahead of print May 6, 2016. DOI: 10.3171/2015.10.SPINE1458]

2. Farhat JS, Velanovich V, Falvo AJ, Horst HM, Swartz A, Patton $\mathrm{JH}$, et al: Are the frail destined to fail? Frailty index as predictor of surgical morbidity and mortality in the elderly. J Trauma Acute Care Surg 72:1526-1531, 2012

3. Fu KMG, Smith JS, Polly DW, Ames CP, Berven SH, Perra $\mathrm{JH}$, et al: Correlation of higher preoperative American Society of Anesthesiology grade and increased morbidity and mortality rates in patients undergoing spine surgery. $\mathbf{J}$ Neurosurg Spine 14:470-474, 2011

4. Grauer JN, Vaccaro AR, Beiner JM, Kwon BK, Hilibrand AS, Harrop JS, et al: Similarities and differences in the treatment of spine trauma between surgical specialties and location of practice. Spine (Phila Pa 1976) 29:685-696, 2004

5. Irwin Z, Hilibrand A, Gustavel M, McLain R, Shaffer W, Myers M, et al: Variation in surgical decision making for degenerative spinal disorder. Part I: lumbar spine. Spine (Phila Pa 1976) 30:2208-2213, 2005

6. Karam J, Tsiouris A, Shepard A, Velanovich V, Rubinfeld I: Simplified frailty index to predict adverse outcomes and mortality in vascular surgery patients. Ann Vasc Surg 27:904-908, 2013

7. Shiloach M, Frencher SK, Steeger JE, Rowell KS, Bartzokis K, Tomeh MG, et al: Toward robust information: data quality and inter-rater reliability in the American College of Surgeons National Surgical Quality Improvement Program. J Am Coll Surg 210:6-16, 2010

8. Tsiouris A, Hammoud ZT, Velanovich V, Hodari A, Borgi J,
Rubinfeld I: A modified frailty index to assess morbidity and mortality after lobectomy. J Surg Res 183:40-46, 2013

\section{Disclosures}

Dr. Fisher is a consultant for Medtronic and NuVasive, and he receives royalties from Medtronic. A grant was paid to his institution by the Orthopaedic Research and Education Foundation (OREF).

\section{Response}

\author{
Rushna Ali, MD,1 Jason M. Schwalb, MD,1 \\ David R. Nerenz, PhD, ${ }^{2}$ Heath J. Antoine, MD, ${ }^{3}$ and \\ Ilan Rubinfeld, MD, MBA ${ }^{3}$
}

1Department of Neurosurgery, Henry Ford Hospital; 2Neuroscience Institute and the Center for Health Policy and Health Services Research, Henry Ford Health System; and ${ }^{3}$ Department of Surgery, Henry Ford Hospital, Detroit, Michigan

We appreciate the positive comments made by Drs. Fisher and Tee in their commentary. On the issue of an appropriate cutoff point for the $\mathrm{mFI}$, we believe that a higher cutoff point would have included moderately to severely frail patients only. As a result, we would have reached a greater statistical significance, but the results might have been less clinically relevant and generalizable. However, we agree with Drs. Fisher and Tee that sensitivity analyses carried out at higher cutoff points would indeed provide useful information, especially now that minimally invasive procedures are being performed more frequently for frailer patients with significant spinal pathology. We hope that our study will pave the way for future studies to assess the utility of $\mathrm{mFI}$ in a prospective manner. 